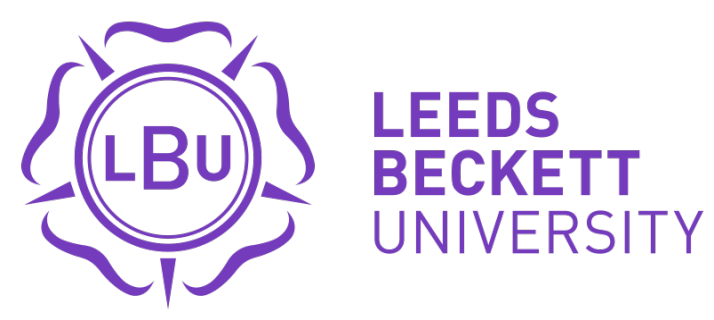

Citation:

Lyle, J (2020) Coaching effectiveness: A personal discourse on bringing clarity to an overused concept. International Sport Coaching Journal, 8 (2). pp. 270-274. ISSN 2328-918X DOI: https://doi.org/10.1123/iscj.2020-0025

Link to Leeds Beckett Repository record:

https://eprints.leedsbeckett.ac.uk/id/eprint/7113/

Document Version:

Article (Accepted Version)

Accepted author manuscript version reprinted, by permission, from International Sport Coaching Journal, 2020, https://doi.org/10.1123/iscj.2020-0025 (C) Human Kinetics, Inc.

The aim of the Leeds Beckett Repository is to provide open access to our research, as required by funder policies and permitted by publishers and copyright law.

The Leeds Beckett repository holds a wide range of publications, each of which has been checked for copyright and the relevant embargo period has been applied by the Research Services team.

We operate on a standard take-down policy. If you are the author or publisher of an output and you would like it removed from the repository, please contact us and we will investigate on a case-by-case basis.

Each thesis in the repository has been cleared where necessary by the author for third party copyright. If you would like a thesis to be removed from the repository or believe there is an issue with copyright, please contact us on openaccess@leedsbeckett.ac.uk and we will investigate on a case-by-case basis. 
Coaching effectiveness: A personal discourse on bringing clarity to an overused concept

Revised $2^{\text {nd }}$ September 2020 


\title{
Coaching effectiveness: A personal discourse on bringing clarity to an overused concept
}

\begin{abstract}
Coaching effectiveness is a ubiquitous term in the sport coaching literature, yet it remains illdefined and challenging to operationalise. This paper explores the concept, and provides a polemic intended to generate discussion within the field. Effectiveness is a more nuanced concept than generally accepted and is best considered a superordinate concept that synthesises other lower-order concepts. Feature matching approaches are most common, but provide, at best, a partial account of effective practice This has also led to a focus on ineffective behaviour. The simplistic notion of effectiveness as goal achievement is not as straightforward as it seems, and, in setting the bar too high, we have equated effectiveness with excellence, rather than simply creating an appropriate effect. Effective coaching should imply that coaches have drawn on their expertise to harness appropriately the resources available in the context of environment and ambition. In this sense, effective coaching is a realisable goal for all coaches; it may or may not lead to performance success. It remains a useful 'unifying label' for reasoning about sport coaching.
\end{abstract}

Keywords: sport coaching; feature matching; superordinate concept; domain specificity; creating effect; expectations.

\section{Introduction}

This Insights paper examines a ubiquitous and enduring theme in our coaching literature - the concept of coaching effectiveness (Gilbert \& Rangeon, 2011). This continues to be a theme that gives focus and direction to academic writing (e.g., Alexander, Bloom \& Taylor, 2020; Flett, Sackett \& Camiré, 2016; Jowett, 2017; Nash \& Mallett, 2019; Santos, et al., 2019). 
Nevertheless, there have been relatively few attempts to deal in depth with the concept itself (Cassidy, Jones \& Potrac, 2009; Denison, Mills \& Jones, 2013; Côté \& Gilbert, 2009; Horn, 2008; Lyle, 2002; North 2017). There is no doubt that this is a concept that exercises the minds of coaching academics. At a more practical level, the pursuit of professionalism, however defined and operationalised, implies that we have some notion of what would constitute effective practice, and that we see the particulars of that practice reflected in coach education and development. If the use of the term is not to be merely a metaphor for understanding coaching practice and its associated expertise, it is surprising that there are so few empirical research papers that address this question directly. This paper will help to explain why this might be the case.

The purpose of this exercise is to stimulate debate, rather than provide yet another synthesis of the literature. Taken-for-granted assumptions about the concept of effectiveness are made more explicit, as is the potential for a consensual approach to the interpretation and utility of the concept. Nevertheless, it would be worthwhile to provide a brief account of some key texts to illustrate the range and development of the approaches taken and to create a backdrop for the debate to come. Lyle (2002), drawing on the earlier literature, highlights three issues: confusion over terminology, overly simplistic reliance on goal achievement, and the importance of context. Horn (2008) collates contributory behaviours, with an emphasis on the psychosocial growth and development of athletes. Côté and Gilbert (2009) provide a definition, which has become a 'root source' for many authors in the field: "the consistent application of integrated professional, interpersonal and intrapersonal knowledge to improve athletes' competence, confidence, connection and character in specific coaching contexts" (p.316). However, their identification of coaching outcomes is partial and drawn largely from youth sport; it reinforces the notion of effectiveness as a descriptor of desirable practice. 
The most recent and theoretically supported treatment of coaching effectiveness is by North (2017). He states that goal orientation is the essential feature for understanding coaching effectiveness and emphasises the 'wider coaching ecology' (p. 269). Effectiveness depends on the contextual 'configuration and collective manipulation' (p.276) through the resources, reasoning, strategies and actions of the many contributing layers of influence. From these brief accounts, it seems clear that the apparent simplicity of the term fails to convey the nuances evident in meaning and operationalisation. This paper aims to identify some of these nuances and to provide an agenda for discussion. It also provides a framework within which coaches, coach developers and academic colleagues can reflect on and evaluate their practice.

\section{Effectiveness as a concept}

We need to begin with a brief overview of what we mean by a concept, in order to provide some structure to the discussion. Semanticists have at their disposal a very wide range of lenses through which to study meaning. I take it for granted that the meaning attached to any word, and its associated use within social groups, is determined and constructed by social convention and interaction. This, inevitably, reflects social differentiation and inequality of power, access and knowledge within those groups. I have adopted a pragmatic theory of meaning; in short, the understanding of a word is determined by the consequences of its application (Rescher, 2012). In other words, the meaning attached to effectiveness may be judged by its usefulness for analysing and evaluating coaching practice or improving coach education and development. This is not as obscure as may first appear. Such an approach leads us to ask four related questions: (a) What would effective practice be intended to achieve? (b) How would we recognise effective practice? (c) What do we need to do to be effective? and (d) How successful is current practice in achieving its ends? 
A concept is a mental abstraction that allows us to generalise about an object, quality or condition and to extend our knowledge and awareness of those from known examples to others unknown. A concept integrates two or more particulars into a common mental unit, with a set of similar characteristics. Thus, effectiveness in sport coaching is a concept that will represent occurrences that have similar properties, necessitating some agreement on those properties. What is considered significant and distinguishing about effective practice will differ according to the purpose for which the concept is being utilised. In making such judgements, concepts have two features that interest us here. The first is a cognitive trigger. An example would be a concern about whether an element of coaching intervention is 'working' or not. The second is a definition that specifies the essential characteristics of the concept. Definitions are about similarities and differences to other concepts. These may, of course, be nuanced differences. Therefore, you may wish to consider what makes coaching practices effective, successful, competent, efficient, or efficacious. The implication is that there is a set of characteristics that would deem practice to be 'successful' and that this would differentiate it, although not necessarily exclude it, from 'effective', and vice versa.

Concepts may usefully be divided into three categories: superordinate, basic and subordinate. The first is a higher-order term, the second more specific and contextual, and the third instance specific. Superordinate concepts are 'discourse-organising words', umbrella terms that include or are dependent upon the meaning of other words. Therefore, concepts have layers of meaning. As a 'collective' concept, coaching effectiveness is useful as a means of communication - a tool to bring order to our thinking. However, it synthesises other lower-order concepts and, therefore, cannot easily be operationalised. We might note here that sport coaching itself is a superordinate concept, perhaps partly explaining why we have so much trouble trying to conceptualise it. Consider how the meaning attached to sport coaching is distilled by our understanding of performance, domains, coaching interventions, 
objectives, causative impact, values, intentions, winning, social relationships, and the role of the coach. A 'root definition' such as that of Côté and Gilbert (2009) has a low level of abstraction but has the advantage of simplicity. Putting it into practice requires contextualisation and operationalisation, which then dilutes its essential meaning. Rather than seeking for root definitions, there would be value in 'operational' definitions. Csatári (2020) suggests that such definitions, "cannot exhaust the meaning of a concept (but) can fix it in a given context" (p. 98). North (2017) agrees that reducing reference to context decreases the value of coaching effectiveness as a guide to development.

One school of thought, prototype theory, argues that concepts need not necessarily have definitions. Coaching effectiveness need not have precise, exhaustive sub-components but a 'feature matching process' takes place, in which the coach's practice satisfies sufficient characteristics of effective practice for it to be so classified. This requires some consensus on what these features might be (e.g. Becker, 2013; Lynn, 2010). The prototype is a mental concept of what 'ideal' practice would look like. We need not react too strongly to the use of 'ideal'. Given what we know about shaping coaching strategies to the context and factoring in the many variables in the process, it is difficult, if not impossible, to identify a 'correct' strategy in detail. Even 'optimum' strategies may be challenging to identify. When used in this context, therefore, 'ideal' should not imply perfection, but merely a principled template. The research of Lara-Bercial \& Mallett (2016) may contribute to this. Nevertheless, some practices that might make coaches more 'effective' (drugs, coercion) would not be deemed acceptable. Therefore, our search is for 'effective practice that we deem acceptable'. We move on now to discuss the operationalisation and applicability of the concept of coaching effectiveness in greater detail.

\section{Sport coaching and effectiveness - discussion issues}


The continuing use of the term coaching effectiveness, albeit as an umbrella concept and often operationalised by partial or proxy measures (Jowett, 2007; Rylander, 2016), attests to its longevity and perceived relevance. Nevertheless, a more thorough examination of its utility is warranted.

\section{Feature matching}

The majority of writers adopt a profiling or feature matching approach. This applies to the listing of behaviours (Becker, 2013), indices of coach-athlete relationships (Forlenza, Pierce, Vealey, \& Mackersie, 2018), environment (Seanor, Schinke, Stambulova, Ross, \& Kpazai, 2017), and practice structures (Light \& Harvey, 2017). However, this approach is also subject to some concerns. Does each of the features of effectiveness contribute equally to the quality of coaching practice, and how, therefore, is prioritisation within and between features to be resolved? At what threshold levels would the criteria for any particular feature of effectiveness be deemed to be satisfactorily evident? In addition, not all characteristics will be similar in nature and evaluation of their extent is perhaps more challenging when the feature to be matched is a 'quality' (c.f., care or compassion, which may themselves be superordinate concepts). Many features fail the test of typicality, and no-one claims to have a completely comprehensive set of criteria of effective coaching. Pedagogy, environment, performance and relationships will each be associated with a set of criteria that may lead to more effective practice but taken in isolation can only render a partial account.

Similarly, the contribution of characteristic behaviours is also problematic. The reality of coaching is that we coaches have recourse, perhaps too quickly, to our favourite approaches to practice. These may represent personal heuristics or favourite routines. However, in the context of complex, dynamic and multi-layered processes, it is challenging to determine whether or not they are achieving what was intended. In addition, not all of the prototype features of complex concepts need be present. The presence or absence of 
particular components, and their perceived contribution to effectiveness, has to be evaluated in the light of myriad contextual circumstances. Indeed, features of some coaching practice may lead us not to seek answers to the accuracy and detail of causative impact. For example, 'the children are happy, so the coaches' actions needn't be examined too closely' or 'the team is winning, so the contribution of the coach needn't be scrutinised in great detail.' Is there a danger, therefore, that we are interested only in 'ineffective' behaviour?

\section{Effective versus ineffective practice}

If coaching practice is judged not to be effective, does this mean that it is 'ineffective'? How does this compare with 'not effective enough' or 'not always effective'? The use of a concept that implies a judgement of quality inevitably brings a question of a threshold point at which practice is no longer effective. This might suggest that there is a wide grey area in which practice is 'not ineffective'. The assumption that all minimally-certificated practising coaches will be effective does not have a ring of face validity to it - perhaps they are 'effective at what they are capable of achieving' and should not be asked to do more. Should effectiveness be judged only in the context of emergent expertise? If this is the case, we must be careful not to equate inexperience with ineffectiveness. Inexperience suggests that aspects of expertise that allow the coach to depend on accumulated responses and routines have not yet fully developed. It is also likely that accumulated knowledge is not yet extensive. This need not imply ineffectiveness, but that the coach may be effective in achieving a lesser range of outcomes and in fewer circumstances.

In addition to being expertise dependent, there are also issues in evaluating effectiveness. It seems likely that it is too complex a judgement to be dependent on a simple threshold measure. There must be gradations of effectiveness. If we accept the 'particularity of the coaching context' argument, consider whether it is possible for all coaches to be effective. We would expect all doctors to be effective - but are some more effective than 
others? Is there a taken-for-granted assumption that 'effective' is a 'sifting descriptor', that is, a label applied only to some coaches? Consider whether you think that 'effective' could apply to everyone. With a simple definition of 'producing an effect', it is likely that the majority of coaches would be effective to some degree. However, the question 'is the effect feasible, appropriate and commensurate' remains. It is possible, therefore, to use the term merely to designate satisfactory or expected coaching practice, without necessarily implying a higher order of practice.

\section{Achieving objectives}

At its most simplistic, effectiveness is equated with the achievement of objectives. We might assume for this purpose that this is based on two suppositions: (a) there is a definable, perhaps measurable, outcome intended; and (b) the actions taken in pursuit of this outcome are purposive, goal-orientated and attributable. It is commonly held that coaches (and other stakeholders) set goals and that these act as signposts for the coaching process. Although there can be little argument against the centrality of goal attainment, subsequent discussion will demonstrate that the relationship is more nuanced than first appears. For example, to what extent can coaches be held accountable for the achievement of objectives? Objectives should be agreed with resources in mind, and with the involvement of the athletes. Such involvement is usually based on a rationale of moral rectitude and in the context of youth sport. The engagement of the athletes is also dependent on the personal resource (knowledge, experience, insight) available to them. In practice, particularly in high performance or professional sport, objectives may be established by other stakeholders. Should coaches be held accountable for objectives set by others? There is also a fine distinction between setting goals in the context of resources, and subsequently judging attainment in the light of the resources available. 
There are further challenges associated with the judgement of what constitutes an appropriate level of achievement. Is it reasonable to make a judgement about effectiveness when the objectives are unrealistic? Similarly, if the objectives set are not challenging, can achieving them be considered a demonstration of effectiveness? Goal setting is part of the planning process and goals are subject to amendment when they are threatened or become unattainable. Objectives may be amended to a level at which they are attainable. Is this contingent thinking part of effectiveness? Evaluating whether goals are 'pitched' appropriately may have few substantive reference points. For example, if objectives are stated in terms of 'improvement' - itself a common criterion of effective practice - when is enough, enough? Sport coaching deals, for the most part, with 'development'. This is an open-ended and variable measure and conceived within assumed but vague parameters established by the athlete's 'potential'. The notion of 'value-added' is a tempting prize as a measure of effectiveness but is far from immediately realisable.

There are also issues with the goals themselves. Outcome goals can be relative or absolute. The former, characteristic of game sports, is evaluated relative to other performers. The latter may be assessed by 'scores' or times/distances. Relative objectives are more difficult to reconcile, particularly in a team context. With relative outcomes, coaches often have recourse to the quality of the 'performance'. Although 'key performance indicators' can be identified, they are also dependent on the quality of the opposition, and difficult to evaluate. It is important to remember that outcome goals in sport are contested, and other coaches and athletes are often intent on achieving the same goals.

\section{Input-output and operationalising}

In the performance domain, outcome measures, such as win-loss record, are considered to be significant. However, we might argue that, for the coach, this represents 'success by association' rather than effectiveness. It raises the distinction between what might be termed 
input measures, that is, particular behaviours or environment, and output measures, that is, athlete performance or other psychosocial or developmental objectives. The limitations of identifying particular behaviours as being, at best, partial representations of practice have already been mentioned. However, we might also find some merit in distinguishing between effectiveness as an external evaluation and effectiveness as an internal 'driver' for the coach. An internal mental model of effectiveness may constitute a conscious or subconscious standard that forms a mirror against which the coach can evaluate whether day-to-day practice is contributing to immediate and longer-term expectations. Identifying the measures used for this - athlete responses, performance targets, progress measures - is an underresearched area. A further complication is the distinction between capacity and performance in coaching. Capacity might be equated with expertise, whereas performance is the coaching practice associated with a particular coaching relationship or period of time, that is, a specific contextualised instance. This is relevant because a reasonable question is whether effectiveness can be judged from a specific instance or over a period of time and circumstance. Being an effective coach doesn't mean that I'll be effective every time, or does it?

The emphasis on inputs can also be focused on the environment within which the coach and athlete(s) operate. This includes the question of coaching domains and may refer to the interpersonal or motivational climate. The concept of effectiveness may be applied across domains but only at a superordinate level. Can you be considered effective in high performance sport without regard for results? Can the coach be considered to be effective in youth sport if there is too much emphasis on performance outcomes? In this context, consider the contribution of value frameworks. These provide a guide for the coach's actions but may point to desirable rather than effective practice. Nevertheless, they raise a number of issues. First, is there a link between effective and 'acceptable'? This is an area that academics have 
rarely dealt with. Presumably, it could be argued that effectiveness need not depend on moral behaviour. Coaches may achieve domain-specific objectives without being 'nice people' or having little regard for the welfare of their athletes. At a practical level, it may be safer to assume that any attribution of meaning comes with a measure of social interpretation but note the danger of 'acceptable' practice being defined within subcultural norms. Second, is it possible to be considered effective in one part of the coaching role but not in another? There may be an argument for being considered effective or less effective in, for example, match coaching, crisis management, interpersonal relationships or planning.

In relation to output measures, there will be some measure of agreement about performance improvement and display being central to sport coaching, but any familiarity with the coaching literature will demonstrate that it rarely features in research as an outcome variable. Athlete satisfaction measures are much more prevalent (Lyle, 2018) and outcomes are expressed in terms of athlete dispositions (Nichol, Hall, Vickery \& Hayes, 2019). There are relatively few attempts to demonstrate links between specific coaching interventions or behaviours and performance improvements. However, sport is also a very valuable tool in education, personal development, building social capital and recreational activity. Performance outcomes are not always central to achieving objectives in these contexts. Leadership in such contexts may, therefore, be subject to a different set of features of effectiveness. The results of this are evident in an emphasis on social and relational aspects of coaching, and attention to delivery behaviour rather than content. It would be difficult to argue that this was a result of prioritising those elements within the coaching process that are likely to impact on performance outcomes. The coaching process is an instrumental coordination and aggregation of an appropriate intervention strategy, efficient micro- and macro-management of delivery, and athlete 'buy-in' - all in the context of available resources and organisational constraints. It is difficult to escape the conclusion that we academics are 
happier in our disciplinary comfort zone than in the complex task of divining coaching effectiveness in the real world. There is a danger that the concept of effectiveness can be appropriated by a partial account of coaching and the resources available with which to interrogate it.

\section{Conclusion}

Effectiveness has been shown to be a superordinate concept. It is a collective label that embraces many other concepts and sub-processes and is most appropriately understood as a contextualised and layered concept. Despite a number of challenges for researchers in operationalising the concept, it may be considered a useful unifying term for reasoning about sport coaching. It was argued that effective means, 'doing the job as it is expected to be done' and that our lens may have been focused on implied excellence rather than effectiveness. It was also noted that the rationale for isolated feature matching research is that it will lead to 'more effective' practice. This claim is easy to make but difficult to demonstrate. However, the fault does not lie with the identification of proxy measures or partial discipline-led features of effectiveness but with our inability to identify a consensual indicator with which to judge their impact.

The paper is intended to be a polemic and to stimulate a more nuanced thinking about coaching concepts. However, there are implications for researchers, coach developers and coaching practitioners. The key message for researchers is that they should associate their models of coaching effectiveness more directly with athlete performance and with contextualised coaching practice rather than non-contextualised measures of coaching capacity. Discipline-specific methods are more applicable to selective prototype 'features' of effectiveness but interdisciplinary and more action-orientated pragmatic approaches are not yet evident. There is value in embedding researchers in specific coaching contexts and investigating the impact of coaches' performance-related intervention strategies. The 
challenge for the researcher is operationalising the cognitive demands inherent in Cote \& Gilbert's (2009) 'consistent application' and North's (2017) 'configuration and collective manipulation'. Nevertheless, researchers should continue to investigate how, in given circumstances, particular combinations of actions can be shown to lead to 'more effective' practice.

Coach development is most often targeted at particular elements of coach's expertise. There would be considerable merit in situating development within a clear model of effectiveness and identifying the contribution that development is expected to make to effective coaching practice. This would allow developers to identify 'break points' in the coach's practice that can be assumed to constitute barriers to more effective practice and would merit attention. Development strategies should recognise the distinction between facilitating (e.g. reflective practice, problem solving), interpersonal and performance-related elements (e.g. planning, competition management, decision policies) and their respective contributions to coaching effectiveness.

For the practitioner, the notion of being 'more effective' is an entirely appropriate aspiration. Coaches should be encouraged to reflect critically on what within their practice appears to be working well and what is less effective. This should lead to a focus on both the contributory elements of their expertise and how they integrate these into their practice in a way that addresses particularised needs and expectations. Developing a 'cognitive reference point' for working effectively may be more helpful than any concern about threshold evaluations of effectiveness.

We are left with the question of whether effectiveness, despite its ubiquity, is a useful concept. Effectiveness implies deploying one's expertise and working practices to achieve appropriate objectives within resource constraints. However, there is an evident need to distinguish between what is implied by effectiveness, how we would recognise it, and the 
means through which greater effectiveness can be achieved. We should avoid defining effectiveness by the presence or absence of specific criteria, thereby mixing process with outcome. Concern about effectiveness may be an academic and perhaps coach developer concern. The real world is happy to deal with success and evident ineffectiveness. Attention to isolated features of behaviour and practice has painted a picture of ineffectiveness, when effective practice is likely to be more prevalent than such deficit-reducing analyses might suggest. In setting the bar too high, we have equated effectiveness with excellence, when it should apply merely to creating an intended and expected effect. A broader aggregation of stakeholder satisfaction, goal achievement and peer-assessable practices may not have the precision that we would wish for. On the other hand, those who argue that effectiveness simply equates to 'good coaching' may not be far off the mark.

\section{References}

Alexander, D., Bloom, G. A., \& Taylor, S. (2020). Female Paralympic athlete views of effective and ineffective coaching practices. Journal of Applied Sport Psychology, 32(1), 48-63. Doi: 10.1080/10413200.2018.1543735

Becker, A. J. (2013). Quality coaching behaviours. In P. Potrac, W. Gilbert \& J. Denison (Eds.), Routledge handbook of sports coaching (pp. 184-195). London: Routledge.

Cassidy, T., Jones, R. L., \& Potrac, P. (2009). Understanding sports coaching: The social, cultural and pedagogical foundations of coaching practice. $2^{\text {nd }}$ edition. London: Routledge.

Côté, J., \& Gilbert, W. D. (2009). An integrative definition of coaching effectiveness and expertise. International Journal of Sports Science \& Coaching, 4(3), 307-323. Doi: $10.1260 / 174795409789623892$

Csatári, F. (2020). Measurement and meaning. Lanham, Md: Lexington Books. 
Denison, J., Mills, J., \& Jones, L. (2013). Effective coaching as a modernist formation: A Foucauldian critique. In P. Potrac, W. Gilbert \& J. Denison (Eds.), Routledge handbook of sports coaching (pp. 388-399). London: Routledge.

Flett, M. R., Carson Sackett, S., Camiré, M (2016). Understanding effective coaching: Antecedents and consequences. In R. Thelwell, C. Harwood \& I. Greenlees (Eds.), The psychology of sports coaching: Research and practice (pp. 156-169). London: Routledge.

Forlenza, S. T., Pierce, S., Vealey, R. S., \& Mackersie, J. (2018). Coaching behaviours that enhance confidence in athletes and teams. International Sport Coaching Journal, 5(3), 205-212. Doi: 10.1128/iscj.2017-0040

Gilbert, W., \& Rangeon, S. (2011). Current directions in coaching research. Revista de Iberoamericana de Psicología del Ejercicio el Deporte, 6(2), 217-236.

Horn, T. S. (2008). Coaching effectiveness in the sport domain. In T. S. Horn (Ed.), Advances in sport psychology (pp. 239-267). Champaign, Il: Human Kinetics.

Jowett, S. (2017). Coaching effectiveness: The coach-athlete relationship at its heart. Current Opinion in Psychology, 16, 154-158. Doi: 10.1016/j.copsyc.2017.05.006

Lara-Bercial, S., \& Mallett, C. J. (2016). The practices and developmental pathways of professional and Olympic serial winning coaches. International Sport Coaching Journal, 3(3), 221-239. Doi: 10.1123/iscj.2016-0083

Light, R. L., \& Harvey, S. (2017). Positive pedagogy for sport coaching. Sport, Education and Society, 22(2), 271-281. Doi: 10.1080/13573322.2015.1015977

Lyle, J. (2002). Sports coaching concepts: A framework for coaches' behaviour. London: Routledge.

Lyle, J. (2018). The transferability of sport coaching research: A critical commentary. Quest, 70(4), 419-437. Doi: 10.1080/00336297.2018.1453846 
Lynn, A. (2010). Effective sports coaching: A practical guide. Marlborough: Crowood Press.

Martin, J. J., \& Whalen, L. (2014). Effective practices of coaching disability sport. European Journal of Adapted Physical Activity, 7(2), 13-23. Doi: 10.5507/euj.2014.007

Nash, C., \& Mallett, C.J. (2019). Effective coaching in football. In E. Konter, J. Beckmann \& T. M. Loughead (Eds.). Football psychology: From theory to practice (pp. 101-116). London: Routledge.

Nichol, A.J., Hall, E.T., Vickery, W., \& Hayes, P.R. (2019). Examining the relationship between coaching practice and athlete "outcomes": A systematic review and critical realist critique. International Sport Coaching Journal, 6(1), 13-29. Doi: 10.1123/iscj2017-0105

North, J. (2017). Sport coaching research and practice: Ontology, interdisciplinarity and critical realism. London: Routledge.

Rescher, N. (2012). Pragmatism: The Restoration of its scientific roots. London: Routledge Rylander, P. (2016). Coaches' bases of power and coaching effectiveness in team sports. International Sport Coaching Journal, 3(2), 128-144. Doi: 10.1123/iscj.2015-0046

Santos, F., Corte-Real, N., Regueiras, L., Dias, C., Martinek, T. S., \& Fonseca, A. (2019). Coaching effectiveness within competitive youth football: youth football coaches' and athletes' perceptions and practices. Sports Coaching Review, 8(2), 172-193. Doi: $10.1080 / 21640629.2018 .1459356$

Seanor, M., Schinke, R.J., Stambulova, N. B., Ross, D., \& Kpazai, G. (2017). Cultivating Olympic champions: A trampoline development environment from grass roots to podium. Journal of Sports Psychology in Action, 8(2), 96-108. Doi: $10.1080 / 21520704.2017 .1327908$ 